\title{
Transcranial direct current stimulation in patients with Alzheimer's disease: challenges and responses
}

\author{
Hong Yuan ${ }^{1}$, Serik Tabarak ${ }^{1}$, Jing Yu, Xu Lei \\ Faculty of Psychology, Southwest University; Key Laboratory of Cognition and Personality; Key research institute of \\ humanities \& social science, Chongqing, 400715, China.
}

*Corresponding Author: E-mail: yuanyh@swu.edu.cn; Tel.: +86-023-6836-7489; Fax: +86-023-6825-3629

${ }^{1}$ These authors contributed equally to this work.

Received: July 06, 2015; Revised: August 18, 2015; Published: September 05, 2015

\begin{abstract}
The use of transcranial direct current stimulation (tDCS) as a noninvasive therapeutic approach for Alzheimer's disease ( $A D)$ has gained increasing attention. Research regarding the utility of $t D C S$ in $A D$ is inconsistent. In this study, we reviewed the importance of individual diversity among $A D$ patients, starting with uninformative mean results. We also demonstrated variations among $A D$ patients. Highly educated patients seemed to benefit more from therapy; education also seems to modulate baseline measurements and results. Individual cortical morphology also affects current distribution, which influences the effectiveness of stimulation. We suggest using structural MRI to distinguish inter-individual variability; high-resolution modeling may also be used to predict current distributions and should be combined with cognitive training (CT) and tDCS.
\end{abstract}

\section{Keywords}

Individual diversity; cortical morphology; educational level; current distribution; cognitive training

\section{Introduction}

Alzheimer's disease (AD) is a major form of age-related dementia and currently affects over 35 million people worldwide (http://www.alz.co.uk/research/world-report). It is associated with impaired episodic memory, as well as other cognitive abilities such as word retrieval, language comprehension, calculation, visuospatial orientation, learning capacity, abstract thinking and judgment [1]. Moreover, it induces changes in personality and disturbs mood [2]. Currently, there is no effective therapy for $A D$, and pharmacological treatments are associated with significant adverse effects [3]. The substantial costs and social burden of $A D$ demand alternative or complementary and low-cost therapeutic treatments for this disease. In this context, non-pharmacological interventions have gained increasing attention in recent years. Such interventions include non-invasive brain stimulation techniques such as transcranial direct current stimulation (tDCS) and transcranial magnetic stimulation (TMS) [4], particularly in combination with cognitive training [5].

In tDCS, the current is passed through saline-soaked sponge electrodes on the scalp, penetrates the skull and influences neuronal function. Cathodal tDCS (ctDCS) suppresses cortical activity, anodal tDCS (atDCS) 
has an activating effect, and sham current is used as a placebo [6]. As a type of non-invasive brain stimulation, tDCS helps to improve various cognitive functions, including motor activity [7], executive function and language ability [8]. Compared with rTMS, which is applied above the active threshold, tDCS modulates brain activity through low-intensity electrical currents (1 to $2 \mathrm{~mA}$ ); tDCS also has fewer side effects and is less invasive, less expensive, easier to use, better controlled, and potentially portable [7]. Moreover, with respect to randomized, double-blinded trials, it is difficult to distinguish real tDCS from sham stimulation because of its subthreshold modulation.

The mechanism of tDCS in AD may be related to brain-derived neurotrophic factor (BDNF). BDNF is required for the survival and synaptic growth of cells compromised by AD [9]; decreased BDNF levels are related to oligomeric amyloid, the major toxic species in $A D$ [10], and correlate with neurodegeneration [11-13]. Decreased BDNF levels also cause defects in long-term potentiation and memory, which correlate with cognitive decline [14-16]. tDCS induces changes in the neuronal membrane resting threshold and contributes to plasticity changes [8]. These effects may occur via the BDNF gene [17].

The existing reviews of tDCS for AD have focused on study design, stimulus parameters and locations $[3,8,18]$. Notably, before these reviews, all of the studies regarding tDCS in AD have demonstrated its effect. Three additional studies regarding tDCS in AD were published after these reviews, but the results of these studies were inconsistent. Herein, we discuss variations observed among affected individuals, which may determine the effectiveness of tDCS in the treatment of AD. These variations include differences in the local structure of both grey and white matter, educational level and cortical morphology. Studying these factors may help us to better understand the scope of the application of tDCS and its limitations.

\section{Variability of individual response}

Mean results may be uninformative in behavioral experiments, particularly when the inclusion criteria for the subjects are based only on a cognitive neuropsychology test. Researchers typically focus on changes in the mean response associated with an experimental manipulation. However, this averaging ignores large variations in individual responses [19]. According to our screening data (Table 1) in which we used mean responses, the effects of tDCS in AD were mixed. Three studies observed a primary effect when they compared anodal and either cathodal or sham groups. Regarding these studies, one observed that atDCS significantly improved recognition memory. Cathodal tDCS significantly decreased word recognition accuracy, whereas sham tDCS did not affect word accuracy. Another study noted that atDCS significantly improved visual recognition memory compared with sham stimulation. Moreover, atDCS also improved visual recognition memory by $8.99 \%$ from baseline, whereas sham stimulation decreased visual recognition memory by $2.62 \%$ [20-22]. The remaining three studies with parallel-sham controlled designs did not observe these effects. In one study, tDCS did not significantly ameliorate memory performance compared with sham tDCS [5]. The other study found no significant differences in apathy after 1 and 2 weeks compared with baseline [23]. The last study found that tDCS improved cognitive function via both anodal and cathodal interventions [24]. We believe that the differences in individual responses are an important source of variation. Furthermore, these types of individual differences may be more obvious in older adults because individual differences in life experience and cognitive abilities increase with age [25]. These differences may be enhanced when parallel-sham controlled study designs are used $[5,23,24]$, as presented in Table 1.

MRI studies of the human brain have demonstrated inter-individual variability in a wide range of basic and higher cognitive functions, including perception, motor control, memory, aspects of consciousness and introspection. This variability may be predicted based on the local structure of grey and white matter, as 
assessed by either voxel-based morphometry or diffusion tensor imaging [19]. Because tDCS is a neuromodulatory tool that influences neuronal function by applying current to specific neural structures, it is important to adequately consider inter-individual differences in the aspects described below.

Table 1. List of patient backgrounds in studies of the use of tDCS as an intervention for AD.

\begin{tabular}{|c|c|c|c|c|c|c|c|}
\hline $\begin{array}{l}\text { Author } \\
\& \text { year }\end{array}$ & $\begin{array}{l}\text { Study } \\
\text { design }\end{array}$ & $\begin{array}{l}\text { Subjects } \\
\text { \& Sex } \\
(\%, M)\end{array}$ & $\begin{array}{l}\text { Screening } \\
\text { methods }\end{array}$ & Age & Diagnosis & $\begin{array}{c}\text { Education \& } \\
\text { years }\end{array}$ & $\begin{array}{c}\text { Results (cognitive } \\
\text { task) }\end{array}$ \\
\hline $\begin{array}{l}\text { Ferrucci } \\
\text { et al. } \\
2008\end{array}$ & $\begin{array}{l}\text { Crossover- } \\
\text { sham } \\
\text { controlled }\end{array}$ & 10,30 & $\begin{array}{c}\text { MMSE } \\
22.7 \pm 1.8\end{array}$ & $75.2 \pm 7.3$ & $\begin{array}{c}\text { NINCDS-ADRDA } \\
\text { \& DSM-IV } \\
\text { [probable] }\end{array}$ & $10.9 \pm 4.8$ & $\begin{array}{c}\text { atDCS }>\text { basline } \\
\text { ctDCS < basline } \\
\text { sham } \\
\text { (word recognition } \\
\text { task) }\end{array}$ \\
\hline $\begin{array}{l}\text { Boggio } \\
\text { et al. } \\
2009\end{array}$ & $\begin{array}{l}\text { Crossover- } \\
\text { sham } \\
\text { controlled }\end{array}$ & 10,40 & $\begin{array}{l}\text { MMSE } \\
17 \pm 4.9\end{array}$ & $79.1 \pm 8.8$ & $\begin{array}{l}\text { NINCDS-ADRDA } \\
\text { [mild-moderate] }\end{array}$ & $8.7 \pm 4.9$ & $\begin{array}{c}\text { atDCS }>\text { sham } \\
\text { (visual recognition } \\
\text { task) }\end{array}$ \\
\hline $\begin{array}{l}\text { Boggio } \\
\text { et al. } \\
2012\end{array}$ & $\begin{array}{l}\text { Crossover- } \\
\text { sham } \\
\text { controlled }\end{array}$ & 15,53 & $\begin{array}{c}\text { MMSE } \\
\text { (1) } 21.0 \pm 3.2 \\
\text { (2) } 19.0 \pm 2.8\end{array}$ & $\begin{array}{l}77.5 \pm 6.9 \\
80.6 \pm 9.5\end{array}$ & $\begin{array}{l}\text { NINCDS-ADRDA } \\
\& \text { DSM-IV }\end{array}$ & $\begin{array}{l}13.3 \pm 4.8 \\
15.7 \pm 0.8\end{array}$ & $\begin{array}{c}\text { atDCS }>\text { basline } \\
\text { sham }<\text { basline } \\
\text { (picture } \\
\text { recognition task) }\end{array}$ \\
\hline $\begin{array}{l}\text { Cotelli } \\
\text { et al. } \\
2014\end{array}$ & $\begin{array}{l}\text { Parallel- } \\
\text { sham } \\
\text { controlled }\end{array}$ & 36,19 & $\begin{array}{c}\text { MMSE } \\
20.1 \pm 2.4\end{array}$ & $\begin{array}{c}76.6 \pm 4.6(\mathrm{AC}) \\
74.7 \pm 6.1(\mathrm{PC}) \\
78.2 \pm 5.2(\mathrm{AM})\end{array}$ & $\begin{array}{l}\text { NINCDS-ADRDA } \\
\text { [mild-moderate] }\end{array}$ & $\begin{array}{l}5.5 \pm 2.4(\mathrm{AC}) \\
8.9 \pm 5.1(\mathrm{PC}) \\
6.3 \pm 2.6(\mathrm{AM})\end{array}$ & $\begin{array}{c}\mathrm{AC}>\mathrm{AM} \\
\mathrm{PC}>\mathrm{AM} \\
\text { (face naming task) }\end{array}$ \\
\hline $\begin{array}{l}\text { Suemoto } \\
\text { et al. } \\
2014\end{array}$ & $\begin{array}{l}\text { Parallel- } \\
\text { sham } \\
\text { controlled }\end{array}$ & 40,30 & $\begin{array}{c}\text { MMSE } \\
15.2 \pm 2.9\end{array}$ & $80.5 \pm 7.5$ & $\begin{array}{l}\text { NINCDS-ADRDA; } \\
\text { Apathy Scale>14 } \\
\text { [moderate - } \\
\text { severe] }\end{array}$ & $4.8 \pm 4.0$ & $\begin{array}{c}\text { atDCS - } \\
\text { sham } \\
\text { (apathy scores) }\end{array}$ \\
\hline $\begin{array}{l}\text { Khedr } \\
\text { et al. } \\
2014\end{array}$ & $\begin{array}{l}\text { Parallel- } \\
\text { sham } \\
\text { controlled }\end{array}$ & 34,55 & $\begin{array}{c}\text { MMSE } \\
18.1 \pm 3.3\end{array}$ & $69.7 \pm 4.8$ & $\begin{array}{l}\text { NINCDS-ADRDA } \\
\text { [mild-moderate] }\end{array}$ & Illiterate & $\begin{array}{l}\text { atDCS > sham } \\
\text { ctDCS > sham } \\
\text { (MMSE scores) }\end{array}$ \\
\hline
\end{tabular}

\section{Education}

Education may serve as an important reference point for differences in individual life experience. Older adults with higher education levels have benefited from tDCS stimulation during a working memory task, whereas individuals with lower education levels did not experience any benefits [26]. As presented in Table 1 , highly educated patients seem benefit more with tDCS [20-22]. One testable hypothesis for this difference is that highly educated patients employ a different strategy than less educated patients. This strategy may enable these highly educated patients to better recruit prefrontal cortex (PFC) structures during specifics tasks. Support for this interpretation comes from a recent neuroimaging study that reported greater PFC activation in expert pilots but not novice pilots performing a track-following task [27]. This finding highlights the need for $\mathrm{CT}$ to develop different strategies to better recruit the PFC; we recommend combining $\mathrm{tDCS}$ with $\mathrm{CT}$, which we will discuss in more detail below.

Effective stimulation and measurements are needed both at baseline and after treatment. The Mini- 
Mental Status Examination (MMSE), which is used in the majority of studies, is a commonly administered measure of global cognitive functioning that is thought to be sensitive to dementia $[5,20-24,28]$. Compared with the traditional cut-off score of 24 for highly educated individuals, a cut-off score of 27 or more generates better estimates among individuals of different ethnicities [29], as less educated and older individuals tend to receive lower scores $[30,31]$, and among illiterate patients, as both atDCS and ctDCS facilitate improvements in MMSE scores compared with sham tDCS [24]. Therefore, educational level also modulates participant recruitment and outcome measures. To effectively compare results across studies, matching patients' backgrounds, including their educations, is important. Moreover, it may also be useful to conduct an IQ test in addition to the MMSE.

\section{Neuropathological variables}

Another critical issue is individual differences in cortical morphology, which influence current flow distribution [32-34]. In AD, cortical atrophy, synaptic damage and ventricular enlargement [35] lead to changes in the volume of cerebrospinal fluid (CSF), which exhibits greater conductivity and therefore significantly alters current pathways [32]. The current parameters used in AD patients are based on models of healthy subjects and clinical trial outcomes, which ignore individual variations in cortical morphology [36]. Moreover, an individual model is supposed to predict current distribution, so that it may effectively modulate the target area.

The first modeling study used a CAD-rendered current flow distribution in the cortex of both healthy and stroke subjects [33]. Follow-up studies considered skull anisotropy, white matter, and gyri resolution and demonstrated the importance of anatomical influences on current flow [37,38]. Nevertheless, these models are often not utilized, most likely because they are difficult to compute. Among the studies of tDCS in AD patients that did not use the modeling approach, Halko et al. observed significant correlations between region-specific $\mathrm{fMRI}$ signals and the locations of stimulating electrodes, which were placed based on individualized MRI head models [39]. For individual models to be routinely used in tDCS studies, they must be easy to derive, and researchers must understand the importance of accurate head models for the determination of current flow and distribution in each patient. This understanding will naturally lead to more studies that may be compared. To better promote individual models, more studies are needed in which predicted current flow distributions are compared with outcomes. This type of model also offers the possibility of reaching deeper structures such as the hippocampus.

\section{Combining tDCS with cognitive training}

Given the increasing use of $C T$ in $A D$, combining tDCS with $C T$ may be even more beneficial. The term "cognitive training" is based on the use of structured methods rather than unspecific and freely managed approaches. The choice of approach depends on the study's purpose. CT may be divided into two basic categories as follows: compensatory and restorative $[40,41]$. Compensatory strategies aim to teach new ways of performing cognitive tasks by working around cognitive deficits. Restorative strategies attempt to improve functioning in specific domains, with the ultimate goal of returning function in these domains to premorbid levels. Both strategies apply equally well to AD. To ameliorate memory impairment in AD and improve recall, the compensatory approach may involve taking relevant notes, and the restorative approach may involve repeated cuing and questioning [42].

In a study of mild to moderate $A D$ patients, patients were randomly assigned to one of the following three study groups: anodal tDCS+individualized computerized (IC) memory training, sham tDCS+IC memory training, and anodal tDCS+motor training. tDCS was then administered during memory training of face- 
name associations (a type of CT). There was general improvement in IC memory performance in both the anodal and sham groups after 2 weeks; this effect was still significant after 12 weeks in the sham group [5]. A case study compared $t D C S+C T$ with sham $+C T$ in individuals with mild $A D$ for 2 months. The results revealed that the combination of $\mathrm{tDCS}+\mathrm{CT}$ had limited effects but stabilized patients' global cognitive function for approximately 3 months and therefore slowed their cognitive decline [28]. Only two studies have combined tDCS with CT; one was a case study, a form of preliminary research. More studies are needed to determine the optimal combination of these two therapies, particularly with respect to the order and timing of the therapies.

These two studies used different orders of stimulation; one used tDCS before CT [28], and the other used tDCS during CT [5]. Older subjects seem to be more sensitive to time course differences compared with younger subjects. One of the studies demonstrated that stimulation before and during the task in young individual exerted equivalent effects, but improvement in picture naming was observed only in the elderly if tDCS was administered during the task [43]. Anodal stimulation during the task may mediate activity-dependent calcium influx and therefore influence task-related plasticity, whereas anodal stimulation before the task may negate task-related plasticity [44]. Nonetheless, these studies are a useful reference for future studies of different $\mathrm{CT}$ tasks.

\section{Conclusion}

Due to growing evidence that tDCS is a promising neurostimulation tool for rehabilitation, tDCS has been used in many studies. However, in studies of tDCS in AD, there has been a wide range of interindividual variability, including the education level of older adults; the mean results of behavioral evaluations may be insufficient to prove its effect. Additionally, individual differences in brain anatomy are extensive; these differences are increased in $A D$ due to the course of the disease and also result in different cognitive disorders in different patients. MRI imaging of the brain is needed to understand individual differences before treatment to apply a precise dosage to the appropriate target region to optimize current flow. Future research should analyze individual baselines and responses and use randomized block designs to explore its different levels. Briefly, as an age-related disease among older adults, AD is suitable for the use of non-invasive tools with relatively small side effects such as tDCS, particularly in combination with CT. Additionally, because it enables flexible dosing, is inexpensive and is well tolerated, we recommend that structural MRI be combined with behavioral data to improve and optimize the effects of tDCS.

\section{Acknowledgements}

Authors are very much thankful to Key Research Institute of Humanities \& Social Science (11SKB21), Southwest University, Chongqing and National Natural Science Foundation of China (NSFC 31300856) for providing financial assistance to carry out this research work.

\section{References}

[1] B.C. Dickerson, H. Eichenbaum, Neuropsychopharmacology 35(1) (2010) 86-104.

[2] J.L. Cummings, H.V. Vinters, G.M. Cole, Z.S. Khachaturian, Neurology 51(1 Suppl 1) (1998) S2-17; discussion S65-67.

[3] R. Nardone, J. Bergmann, M. Christova, F. Caleri, F. Tezzon, G. Ladurner, E. Trinka, S. Golaszewski, Int. J. Alzheimer's Dis. 2012 (2012) 687909.

[4] A. Floel, L.G. Cohen, Neurobiol. Dis. 37(2) (2010) 243-251. 
[5] M. Cotelli, R. Manenti, M. Brambilla, M. Petesi, S. Rosini, C. Ferrari, O. Zanetti, C. Miniussi, Front. Aging Neurosci. 6:38 (2014).

[6] M.A. Nitsche, W. Paulus, J. Physiol. 527 Pt 3 (2000) 633-639.

[7] M.A. Nitsche, L.G. Cohen, E.M. Wassermann, A. Priori, N. Lang, A. Antal, W. Paulus, F. Hummel, P.S. Boggio, F. Fregni, A. Pascual-Leone, Brain Stimul. 1(3) (2008) 206-223.

[8] P.S. Boggio, C.A. Valasek, C. Campanhã, A.C.A. Giglio, N.I. Baptista, O.M.Lapenta, F. Fregni, Neuropsychol. Rehabil. 21(5) (2011) 703-716.

[9] J. Yuan, B.A. Yankner, Nature 407(6805) (2000) 802-809.

[10] M.P. Lambert, A.K. Barlow, B.A. Chromy, C. Edwards, R. Freed, M. Liosatos, T.E. Morgan, I. Rozovsky, B. Trommer, K.L. Viola, P. Wals, C. Zhang, C.E. Finch, G.A. Krafft, W.L. Klein, Proc. Natl. Acad. Sci. USA 95(11) (1998) 6448-6453.

[11] Y. Gong, L. Chang, K.L. Viola, P.N. Lacor, M.P. Lambert, C.E. Finch, G.A. Krafft, W.L. Klein, Proc. Natl. Acad. Sci. USA 100(18) (2003) 10417-10422.

[12] L.F. Lue, Y.-M. Kuo, A.E. Roher, L. Brachova, Y. Shen, L. Sue, T. Beach, J.H. Kurth, R.E. Rydel, J. Rogers, Am. J. Pathol. 155(3) (1999) 853-862.

[13] C.A. McLean, R.A. Cherny, F.W. Fraser, S.J. Fuller, M.J. Smith, K. Vbeyreuther, A.I. Bush, C.L. Masters, Ann. Neurol. 46(6) (1999) 860-866.

[14] M. Korte, P. Carroll, E. Wolf, G. Brem, H. Thoenen, T. Bonhoeffer, Proc. Natl. Acad. Sci. USA 92(19) (1995) 8856-8860.

[15] K. Olofsdotter, O. Lindvall, F. Asztely, Neuroscience 101(3) (2000) 531-539.

[16] S.L. Patterson, T. Abel, T.A.S. Deuel, K.C. Martin, J.C. Rose, E.R. Kandel, Neuron 16(6) (1996) 11371145.

[17] A. Antal, L. Chaieb, V. Moliadze, K. Monte-Silva, C. Poreisz, N. Thirugnanasambandam, M.A. Nitsche, M. Shoukier, H. Ludwig, W. Paulus, Brain Stimul. 3(4) (2010) 230-237.

[18] C. Freitas, H. Mondragon-Llorca, A. Pascual-Leone, Exp. Gerontol. 46(8) (2011) 611-627.

[19] R. Kanai, G. Rees, Nat. Rev. Neurosci. 12(4) (2011) 231-242.

[20] P.S. Boggio, R. Ferrucci, F. Mameli, D. Martins, O. Martins, M. Vergari, L. Tadini, E. Scarpini, F. Fregni, A. Priori, Brain Stimul. 5(3) (2012) 223-230.

[21] P.S. Boggio, L.P. Khoury, D.C.S. Martins, O.E.M.S Martins, E.C. de Macedo, F. Fregni, J. Neurol. Neurosurg. Psychiatry 80(4) (2009) 444-447.

[22] R. Ferrucci, F. Mameli, I. Guidi, S. Mrakić-Sposta, M. Vergari, S. Marceglia, F. Cogiamanian, S. Barbieri, E. Scarpini, A. Priori, Neurology 71(7) (2008) 493-498.

[23] C.K. Suemoto, D. Apolinario, E.M. Nakamura-Palacios, L. Lopes, R.E.P. Leite, M.C. Sales, R. Nitrini, S.M. Brucki, L.S. Morillo, R.M. Magaldi, F. Fregni, Brain Stimul. 7(2) (2014) 308-313.

[24] E.M. Khedr, N.F.E. Gamal, N.A. El-Fetoh, H. Khalifa, E.M. Ahmed, A.M. Ali, M. Noaman, A.A. El-Baki, A.A. Karim, Front. Aging Neurosci. 6:275 (2014).

[25] A. Gutchess, Science 346(6209) (2014) 579-582.

[26] M.E. Berryhill, K.T. Jones, Neurosci. Lett. 521(2) (2012) 148-151.

[27] M. Peres, P.F. Van De Moortele, C. Pierard, S. Lehericy, P. Satabin, D. Le Bihan, C.Y: Guezennec, Aviat. Space Environ. Med. 71(12) (2000) 1218-1231.

[28] B. Penolazzi, S. Bergamaschi, M. Pastore, D. Villani, G. Sartori, S. Mondini, Neuropsychol. Rehabil. (2014) 1-19.

[29] C.C. Spering, V. Hobson, J.A. Lucas, C.V. Menon, J.R. Hall, S.E. O’Bryant, J. Gerontol. A Biol. Sci. Med. Sci. 67(8) (2012) 890-896.

[30] G.M. Nys, M.J.E. van Zandvoort, P.L.M. de Kort, B.P.W. Jansen, L.J. Kappelle, E.H.F. de Haan, Arch. Clin. Neuropsychol. 20(5) (2005) 623-629.

[31] T.N. Tombaugh, N.J. Mclntyre, J. Am. Geriatr. Soc. 40(9) (1992) 922-935.

[32] M. Bikson, A. Rahman, A. Datta, F. Fregni, L. Merabet, Neuromodulation 15(4) (2012) 306-315. 
[33] T. Wagner, F. Fregni, S. Fecteau, A. Grodzinsky, M. Zahn, A. Pascual-Leone, Neuroimage 35(3) (2007) 1113-1124.

[34] T. Wagner, A. Valero-Cabre, A. Pascual-Leone, Annu. Rev. Biomed. Eng. 9 (2007) 527-565.

[35] G.B. Frisoni, N.C. Fox, C.R. Jack Jr, P. Scheltens, P.M. Thompson, Nat. Rev. Neurol. 6(2) (2010) 67-77.

[36] S. Mahdavi, F. Yavari, S. Gharibzadeh, F. Towhidkhah, Front. Comput. Neurosci. 8:72 (2014).

[37] A. Datta, V. Bansal, J. Diaz, J. Patel, D. Reato, M. Bikson, Brain Stimul. 2(4) (2009) 201-207.e1.

[38] H.S. Suh, et al., Conf. Proc. IEEE Eng. Med. Biol. Soc. (2009) 638-641.

[39] M.A. Halko, A. Datta, E.B. Plow, J. Scaturro, M. Bikson, L.B. Merabet, Neuroimage 57(3) (2011) 885891.

[40] A.S. Bellack, J.M. Gold, R.W. Buchanan, Schizophr. Bull. 25(2) (1999) 257-74.

[41] W.D. Spaulding, S.K. Fleming, D. Reed, M. Sullivan, D. Storzbach, M. Lam, Schizophr. Bull. 25(2) (1999) 275-289.

[42] D.I. Sitzer, E.W. Twamley, D.V. Jeste, Acta Psychiatr. Scand. 114(2) (2006) 75-90.

[43] A. Fertonani, M. Brambilla, M. Cotelli, C. Miniussi, Front. Aging Neurosci. 6:131 (2014).

[44] U. Ziemann, H.R. Siebner, Brain Stimul. 1(1) (2008) 60-66.

(C)2015 by the authors; licensee IAPC, Zagreb, Croatia. This article is an open-access article distributed under the terms and conditions of the Creative Commons Attribution license (http://creativecommons.org/licenses/by/3.0/) (cc)) EY 